\title{
Domination Integrity of Some Special Graphs
}

\author{
D. Bhuvaneswari, S. Meenakshi,
}

\begin{abstract}
A major importance is given to the stability of a network by its users and designers. Domination Integrity is one of the parameter used to determine the network's vulnerability and its defined for a connected graph $G$ as “ $D I(G)=\min \{|X|+m(G-X): X$ is a dominating set\} wh ere $m(G-X)$ is the order of maximum component of $G-X$, by Sundareswaran and Swaminathan. Here we investigate the domination integrity of Tadpole graph, Lollipop graph and a line graph of composition of $P_{n}$ and $P_{2}$
\end{abstract}

Keywords : Domination Integrity, Line graph, Lollipop graph, Tadpole graph.

\section{INTRODUCTION}

A communication network composed of processor (or nodes) and connection between the processor as a links. Unfortunately, the destruction of links, disturbance in nodes, any fault in software, hardware and failure of transmission occurs at various terminals (starting and ending points) will result in a disturbance of service for a prolonged duration may affect its effectiveness which is described as a Vulnerability of a network. While constructing the communication network, it must be more stable or vulnerability must be less. On modeling the network as a graph, we number of graph theoretic parameters such as binding number, edge tenacity, integrity, edge integrity, vertex-neighbor integrity, Domination integrity etc. and these are used to estimate the resistance level of a network after the failure of certain elements which happened in the case of a interruptions.

For any modeled graph structure, the vulnerability means that 'any small damage cause large consequences'. In a graph structure, the vulnerability is nothing but the inadequacy of a resistance due to the deletion of vertices or edges or both. On analyzing the vulnerability of a network after any interruption, the two quantities are necessary which are (i) number of non-working elements(edges or nodes), (ii) order or the biggest remaining component or sub network within which mutual communication can exists. Here the first one represents the imperfection (most targeted) nodes for more interruption and the second one provides the consequences after interruption.

Swaminathan and Sundaraeswarn[2]-[5] introduced the

Revised Manuscript Received on December 5, 2019.

D. Bhuvaneswari, Research Scholar, Department of Mathematics, Vels Institute of Science, Technology \& Advanced Studies, Chennai-600117, Tamil Nadu, India. Email: bhuvanamaths15@gmail.com.

S. Meenakshi, Associate Professor, Department of Mathematics, Vels Institute of Science, Technology \& Advanced Studies, Chennai-600117, Tamil Nadu, India. Email: meenakshikarthikeyan@yahoo.co.in concept of domination integrity and investigated the domination integrity of middle graphs, trees and power of cycles.

\section{A. Definition[1]}

A subset $D$ of $V(G)$ is said to be a dominating set of a graph $\mathrm{G}$ if every vertex $u \in V$ is either in D or adjacent to atleast one element in D.

\section{B. Definition[2]}

The Domination integrity of a connected graph $G$ is written as $\mathrm{DI}(\mathrm{G})$ and defined as $\mathrm{DI}(\mathrm{G})=\min \{|\mathrm{X}|+\mathrm{m}(\mathrm{G}-\mathrm{X}): \mathrm{X}$ is a dominating set $\}$ where $\mathrm{m}(\mathrm{G}-\mathrm{X})$ is the order(number of vertices) of a largest component of $\mathrm{G}-\mathrm{X}$.

The Kothari and Vaidya[7]-[9] studied the domination integrity of duplication of a vertex(or an edge) by an edge(or vertex), Splitting graph of path and cycle, and Splitting and degree splitting graph of some graphs. The domination integrity of Shadow graphs of bistar, path, complete bipartite and cycle, some path related graphs and total graphs of star, path and cycle graphs were analyzed by Shah and Vaidya[10]-[12]. Veena and Sulthan seena [6] have investigated the domination integrity of Line Splitting and central graph of some standard graphs. Some basic definitions used here are:

\section{Definition}

The Line graph $\mathrm{L}(\mathrm{G})$ of a graph $\mathrm{G}\left(\mathrm{V}_{\mathrm{G}}, \mathrm{E}_{\mathrm{G}}\right)$ is also a graph with vertex set as $\mathrm{E}_{\mathrm{G}}$ (that is $\mathrm{V}(\mathrm{L}(\mathrm{G})$ ) is a edge set of a graph $\mathrm{G})$, and the two vertices $e_{i}, e_{j}$ are adjacent in $L(G)$ if and only if the edges $e_{i}$ and $e_{j}$ are adjacent in a graph $G$.

\section{Definition}

The $(m, n)$ - Tadpole graph is denoted by $T_{m, n}$ and is obtained by connecting any vertex of cycle $C_{m}$ to the end vertex of the path $P_{n}$ with the bridge and is also named as Kite graph or Dragon graph.

\section{E. Definition}

The Lollipop graph is a graph obtained by linking any vertex of the complete graph $\mathrm{K}_{\mathrm{r}}$ to the end vertex of the path $P_{s}$ with the bridge and is denoted by $K_{r, s}$.

\section{F. Definition}

Let $G_{1}$ and $G_{2}$ be a two graphs with disjoint vertex sets $V_{1}$ and $V_{2}$ and the edges sets $E_{1}$ and $E_{2}$. The composition of two graphs $G_{1}$ and $G_{2}$ (lexicographic product) is also the graph with vertex set $\mathrm{V}_{1}\left(\mathrm{G}_{1}\right) \times \mathrm{V}_{2}\left(\mathrm{G}_{2}\right)$ and the two vertices $\left(\mathrm{u}_{1}, \mathrm{v}_{1}\right)$ and $\left(\mathrm{u}_{2}, \mathrm{v}_{2}\right)$ are adjacent if either $u_{1}$ and $u_{2}$ 
are adjacent in $\mathrm{G}_{1}$ or $u_{1}=u_{2}$ and $\mathrm{v}_{1}$ is adjacent to $\mathrm{v}_{2}$ in $\mathrm{G}_{1}$ and is denoted as $\mathrm{G}_{1}\left[\mathrm{G}_{2}\right]$.

The graphs considered here are undirected, loop less, finite and connected and the terminology used are in [1],[13].

\section{MAIN RESULT}

\section{A. Theorem}

$$
\operatorname{DI}\left(\mathrm{T}_{3, \mathrm{n}}\right)=\left\{\begin{array}{cc}
3, & \mathrm{n}=1, \\
4+\mathrm{i}, & \mathrm{n}=2+3 \mathrm{i}+\mathrm{j}, \\
\text { where } \mathrm{j}=0,1,2 \text { and } \mathrm{i}=\{0\} \cup \mathrm{N}
\end{array}\right.
$$

\section{Proof}

Let $\left|\mathrm{V}\left(\mathrm{T}_{3, \mathrm{n}}\right)\right|=3+\mathrm{n}=\mathrm{p}$ and $\left|\mathrm{E}\left(\mathrm{T}_{3, \mathrm{n}}\right)\right|=3+\mathrm{n}$ of the graph $\mathrm{T}_{3, \mathrm{n}}$. We need two cases to prove the result.

\section{Case (i)}

For $n=1$, Let the vertex of $\mathrm{T}_{3,1}$ be $\mathrm{v}_{1}, \mathrm{v}_{2}, \mathrm{v}_{3}, \mathrm{v}_{4}$. Consider $S=\left\{v_{3}\right\} \quad$ as a dominating set of $\mathrm{T}_{3,1}$ and we get $\mathrm{m}\left(\mathrm{T}_{3,1}-\mathrm{S}\right)=2$. Therefore, $|\mathrm{S}|+\mathrm{m}\left(\mathrm{T}_{3,1}-\mathrm{S}\right)=3$. If we select $\mathrm{a}$ dominating set either $S=\left\{\mathrm{v}_{1}, \mathrm{v}_{4}\right\}$ or $S=\left\{v_{2}, v_{4}\right\}$, we get $m\left(T_{3,1}-S\right)=2$ in both the cases we get $|S|+m\left(T_{3,1}-S\right)=4$.Hence $\operatorname{DI}\left(\mathrm{T}_{3,1}\right)=3$.

\section{Case (ii)}

- If $\mathrm{n}=2+3 \mathrm{i}+\mathrm{j}$ where $\mathrm{j}=0$ and $i=\{0\} \bigcup N$ (that is, for $\quad \mathrm{n}=2,5,8,11, \ldots)$, consider $\mathrm{S}=\left\{\mathrm{v}_{3+3 \mathrm{k}} \backslash \mathrm{k}=0\right.$ to $\left.\mathrm{i}\right\} \bigcup\left\{\mathrm{v}_{3+\mathrm{n}}\right\}$ and $|S|=2+i$.

- If $\mathrm{n}=2+3 \mathrm{i}+\mathrm{j}$ where $\mathrm{j}=1,2$ and $i=\{0\} \bigcup N$ (i.e., for $n=3,4,6,7,9,10,12,13 \ldots \ldots)$, consider the set $\mathrm{S}=\left\{\mathrm{v}_{3+3 \mathrm{k}} \backslash \mathrm{k}=0\right.$ to $\left.\mathrm{i}+1\right\}$ and $|S|=2+i$.

In the above two cases, the set $\mathrm{S}$ is considered as a dominating set because $v_{1}, v_{2}, v_{4} \in N\left(v_{3}\right)$ and $v_{5+3 t}, v_{7+3 t} \in N\left(v_{6+3 t}\right)$ where $\mathrm{t}=0,1,2,3, \ldots \ldots$, and also $\mathrm{m}\left(\mathrm{T}_{3, \mathrm{n}}-\mathrm{S}\right)=2$.

Now we have to check the minimum of $|S|+m\left(T_{3, n}-S\right)$.

Let us consider any other dominating set $\mathrm{S}_{1}$ of $\mathrm{T}_{3, \mathrm{n}}$ with $\mathrm{m}\left(\mathrm{T}_{3, \mathrm{n}}-\mathrm{S}\right)>2$ because due to the nature of the construction of the graph $\mathrm{T}_{3, \mathrm{n}}$, will have $|S| \geq\left|S_{1}\right|$. Therefore,

$$
\left|S_{1}\right|+m\left(T_{3, n}-S_{1}\right)>|S|+m\left(T_{3, n}-S\right)
$$

Consider any other set $\mathrm{S}_{2}$ as a dominating set of $\mathrm{T}_{3, \mathrm{n}}$ with $m\left(T_{3, n}-S\right)<2$, that is each component in $T_{3, n}-S$ will be the isolated point, then automatically $\left|\mathrm{S}_{2}\right|>|\mathrm{S}|$.

$$
|\mathrm{S}|+\mathrm{m}\left(\mathrm{T}_{3, \mathrm{n}}-\mathrm{S}\right) \leq\left|\mathrm{S}_{2}\right|+\mathrm{m}\left(\mathrm{T}_{3, \mathrm{n}}-\mathrm{S}_{2}\right)
$$

Therefore,

$$
\begin{aligned}
|S|+m\left(T_{3, n}-S\right) & =\min \left\{|X|+m\left(T_{3, n}-X\right): X \text { is a dominating set }\right\} \\
& =D I\left(T_{3, n}\right)
\end{aligned}
$$

Hence for $n \geq 2$, we get

$$
\operatorname{DI}\left(\mathrm{T}_{3, \mathrm{n}}\right)=\left\{\begin{array}{cc}
3, & \mathrm{n}=1, \\
4+\mathrm{i}, & \mathrm{n}=2+3 \mathrm{i}+\mathrm{j}, \\
\text { where } \mathrm{j}=0,1,2 \text { and } \mathrm{i}=\{0\} \cup \mathrm{N}
\end{array}\right.
$$

\section{B. Theorem}

$\operatorname{DI}\left(T_{4, n}\right)=\left\{\begin{array}{cr}3, & \text { if } n=1, \\ 4+i, & \text { if } n=2+2 i+j \text { where } j=0,1 \text { and } i=\{0\} \cup N, \\ 7+i, & \text { if } n=8+3 i+j \text { where } j=0,1,2 \text { and } i=\{0\} \cup N,\end{array}\right.$

Proof

Let

$$
V\left(T_{4, n}\right)=\left\{v_{1}, v_{2}, v_{3}, \ldots . v_{4+n}\right\}
$$

and

$\left|\mathrm{E}\left(\mathrm{T}_{4, \mathrm{n}}\right)\right|=\left|\mathrm{V}\left(\mathrm{T}_{4, \mathrm{n}}\right)\right|$. The proof is given by the following three cases.

Case (i)

If $\mathrm{n}=1$, then the vertex set of $\mathrm{T}_{4,1}$ is $\left\{\mathrm{v}_{1}, \mathrm{v}_{2}, \mathrm{v}_{3}, \mathrm{v}_{4}, \mathrm{v}_{5}\right\}$. Now, consider the set $S=\left\{v_{2}, v_{4}\right\}$ as a dominating set of $\mathrm{T}_{4,1}$ then we have $\mathrm{m}\left(\mathrm{T}_{4,1}-\mathrm{S}\right)=1$ So $|\mathrm{S}|+\mathrm{m}\left(\mathrm{T}_{4,1}-\mathrm{S}\right)=3$. The other possible dominating set of $T_{4,1}$ are $\mathrm{S}=\left\{\mathrm{v}_{1}, \mathrm{v}_{4}\right\}$ and $\mathrm{S}=\left\{\mathrm{v}_{1}, \mathrm{v}_{3}, \mathrm{v}_{5}\right\}$, then we have $|S|+m\left(T_{4,1}-S\right)=4$.

Among all these dominating set, $|S|+m\left(T_{4,1}-S\right)=2+1=3$ is minimum.

Case (ii) For $2 \leq \mathrm{n} \leq 7$

- If $\mathrm{n}=2,3$ and 5, consider the set $S=\left\{v_{2+2 k} \backslash \mathrm{k}=0\right.$ to $\left.\mathrm{i}+2\right\}$ and $|S|=3+i$. Moreover we have $m\left(T_{4, n}-S\right)=1$.

- If $\mathrm{n}=4,6$ and 7 , then choose the set $S=\left\{v_{2}, v_{4}\right\} \bigcup\left\{v_{7+3 k} \backslash \mathrm{k}=0\right.$ to $\left.\mathrm{i}-1\right\}$ and $|S|=2+i$. Further, we have $m\left(T_{4, n}-S\right)=2$. Then for also $S=\left\{v_{2+2 k} \backslash \mathrm{k}=0\right.$ to $\left.\mathrm{i}+2\right\}$ and $|S|=3+i$ we have $m\left(T_{4,1}-S\right)=1$. So for both the set $\mathrm{S}$, we get $|S|+m\left(T_{4, n}-S\right)=4+i$.

The above mentioned set $\mathrm{S}$, will be a dominating set as $v_{1}, v_{3}, v_{5} \in N\left(V_{4}\right)$ and $v_{6+3 t}, v_{8+3 t} \in N\left(v_{7+3 t}\right)$ for $\mathrm{t}=0,1.2 \ldots \ldots$

Now to analysis the minimality of $|S|+m\left(T_{4, n}-S\right)$ :

Let $S_{1}$ be any other dominating set with $m\left(T_{4, n}-S_{1}\right)>2$, then it is easily verified that,

$$
|S|+m\left(T_{4, n}-S\right) \leq\left|S_{1}\right|+m\left(T_{4, n}-S_{1}\right)
$$

Now for another dominating set $S_{2}$ with $m\left(T_{4, n}-S_{2}\right)=1$, then each component in $T_{4, n}-S_{2}$ is a isolated vertex. So,

$$
|S|+m\left(T_{4, n}-S\right) \leq\left|S_{2}\right|+m\left(T_{4, n}-S_{2}\right)
$$

Hence from (3) and (4), $D I\left(T_{4, n}\right)=4+i$.

Case (iii)

Let $S_{1}=\left\{v_{2}, v_{4}\right\}$.

- If $\mathrm{n}=8+3 \mathrm{i}+\mathrm{j}$ where $\mathrm{j}=0$ and $i=N \bigcup\{0\}$

$$
\text { ( i.e. for } n=8,11,14,17 \ldots \text { ), then }
$$


$S=S_{1} \bigcup\left\{v_{7+3 k} \backslash \mathrm{k}=0\right.$ to $\left.\mathrm{i}+1\right\}$ and $|S|=5+i$.

- If $\mathrm{n}=8+3 \mathrm{i}+\mathrm{j}$ where $\mathrm{j}=1,2$ and $i=N \bigcup\{0\}$ (i.e for $\quad \mathrm{n}=9,10,12,13,15,16 \ldots \ldots), \quad$ then $S=S_{1} \bigcup\left\{v_{7+3 k} \backslash \mathrm{k}=0\right.$ to $\left.\mathrm{i}+2\right\}$ and $|S|=5+i$.

For the above mentioned set $\mathrm{S}$ in $T_{4, n}$ will be a dominating set as $v_{1}, v_{3}, v_{5} \in N\left(v_{4}\right)$ and $v_{6+3 t}, v_{8+3 t} \in N\left(v_{7+3 t}\right)$ for $\mathrm{t}=0$, $1,2 \ldots$. and we have $m\left(T_{4, n}-S\right)=2$.

Now to verify the minimality of $|S|+m\left(T_{4, n}-S\right)$ :

Let us consider any other dominating set as $S_{1}$ with $m\left(T_{4, n}-S\right)>2$, then due to the nature of the structure of $T_{4, n}$, we get $\left|S_{1}\right| \geq|S|$ such that

$$
\left|S_{1}\right|+m\left(T_{4, n}-S_{1}\right) \geq|S|+m\left(T_{4, n}-S\right)
$$

Now, $S_{2}$ is any other dominating set with $m\left(T_{4, n}-S\right)<2$, (i.e $m\left(T_{4, n}-S\right)=1$ ), then obviously $\left|S_{2}\right|>|S|$. So

$$
\left|S_{2}\right|+m\left(T_{4, n}-S_{2}\right) \geq|S|+m\left(T_{4, n}-S\right)
$$

Therefore by (5) and (6),

$|S|+m\left(T_{4, n}-S\right)=\min \left\{|X|+m\left(T_{4, n}-X\right): \mathrm{X}\right.$ is a dominating set $\}$

$$
=D I\left(T_{4, n}\right)
$$

Hence

$$
\operatorname{DI}\left(\mathrm{T}_{4, \mathrm{n}}\right)=\left\{\begin{array}{cc}
3, & \text { if } \mathrm{n}=1, \\
4+\mathrm{i}, & \text { if } \mathrm{n}=2+2 \mathrm{i}+\mathrm{j} \text { where } \mathrm{j}=0,1 \text { and } \mathrm{i}=\{0\} \cup \mathrm{N}, \\
7+\mathrm{i}, & \text { if } \mathrm{n}=8+3 \mathrm{i}+\mathrm{j} \text { where } \mathrm{j}=0,1,2 \text { and } \mathrm{i}=\{0\} \cup \mathrm{N},
\end{array}\right.
$$

\section{Theorem}

For $m \geq 5$

$$
D I\left(T_{m, 1}\right)=\left\{\begin{array}{cc}
4, & \text { if } m=5,6 \\
5+i, & \text { if } m=7+3 i+j, \text { where } \mathrm{j}=0,1,2 \text { and } \mathrm{i}=\mathrm{N} \cup\{0\}
\end{array}\right.
$$

Proof

Let the $\left|V\left(T_{m, 1}\right)\right|=m+1$. The proof is given by the two cases.

Case (i)

For $m=5$

Let us consider $S=\left\{v_{2}, v_{5}\right\}$ as a dominating set of $T_{5,1}$, then $m\left(T_{5,1}-S\right)=2$. So $|S|+m\left(T_{5,1}-S\right)=4$. For any other choice of $S=\left\{v_{1}, v_{4}, v_{6}\right\}$ or $\left\{v_{2}, v_{3}, v_{6}\right\}$ we have $m\left(T_{5,1}-S\right)$ as 5 and 6 respectively. So $|S|+m\left(T_{5,1}-S\right)=2+2=4$ is minimum. Hence $D I\left(T_{5,1}\right)=4$.

If $\mathrm{m}=6$, consider $S=\left\{v_{2}, v_{6}\right\}$ as a dominating set of $T_{6,1}$, then $m\left(T_{6,1}-S\right)=2$. So $|S|+m\left(T_{6,1}-S\right)=4$. For any other choice of $S=\left\{v_{2}, v_{5}, v_{7}\right\}$ or $S=\left\{v_{1}, v_{3}, v_{5}, v_{7}\right\}$ we have $m\left(T_{6,1}-S\right)$ as 2 and 1 respectively.

So $|S|+m\left(T_{6,1}-S\right)=2+2=4$ is minimum. Therefore, $\operatorname{DI}\left(T_{6,1}\right)=4$.

\section{Case (ii)}

If $\mathrm{m}=7+3 \mathrm{i}+\mathrm{j}$, where $\mathrm{j}=0,1,2$ and $i=N \bigcup\{0\}$ (i. e., for $\mathrm{m}=7,8,9,10,11,12, \ldots .$.$) , then consider the dominating$ set $S=\left\{v_{3+3 k} \backslash \mathrm{k}=\mathrm{o}\right.$ to $\left.\mathrm{i}+1\right\} \bigcup\left\{v_{m}\right\} \quad$ and $|S|=3+i$, $m\left(T_{m, 1}-S\right)=2$. So $|S|+m\left(T_{m, 1}-S\right)=3+i+2$.

If for any other dominating set $S_{1}$ with $m\left(T_{m, 1}-S_{1}\right) \geq 2$, then due to the nature of the structure of $T_{m, 1}$, we get $\left|S_{1}\right| \geq|S|$ such that

$$
\left|S_{1}\right|+m\left(T_{m, 1}-S_{1}\right) \geq|S|+m\left(T_{m, 1}-S\right)
$$

Let $S_{2}$ be any other dominating set of $T_{m, 1}$ with $m\left(T_{m, 1}-S\right)<2$, (i. e, $m\left(T_{m, 1}-S\right)=1$ ), then obviously we say that $\left|S_{2}\right|>|S|$. So

$$
\left|S_{2}\right|+m\left(T_{m, 1}-S_{2}\right) \geq|S|+m\left(T_{m, 1}-S\right)
$$

From (7) and (8), we get

$|S|+m\left(T_{m, 1}-S\right)=\min \left\{|X|+m\left(T_{m, 1}-X\right): \mathrm{X}\right.$ is a dominating set $\}$

$$
=D I\left(T_{m, 1}\right)
$$

Hence,

For $m \geq 5$

$D I\left(T_{m, 1}\right)=\left\{\begin{array}{cc}4, & \text { if } m=5,6 \\ 5+i, & \text { if } m=7+3 i+j, \text { where } \mathrm{j}=0,1,2 \text { and } \mathrm{i}=\mathrm{N} \bigcup\{0\}\end{array}\right.$

\section{Theorem}

For $\mathrm{m}=5,6$ and $n \geq 2$

$$
D I\left(T_{m, n}\right)=5+i, \text { if } \mathrm{n}=2+3 \mathrm{i}+\mathrm{j} \text {, where } \mathrm{j}=0,1,2 \text { and } \mathrm{i}=\mathrm{N} \cup\{0\}
$$

\section{Proof}

Let $\left|V\left(T_{m, n}\right)=m+n\right|$. To prove this we need the following two cases.

Case (i) For $m=5$

- If $\mathrm{n}=2+3 \mathrm{i}+\mathrm{j}$, where $\mathrm{j}=0,1$ and $i=N \bigcup\{0\}$,

$$
\begin{aligned}
& \text { Consider the } \\
& S=\left\{v_{2+3 k} \backslash \mathbf{k}=\mathbf{O} \text { to } \mathbf{i}+1\right\} \cup\left\{v_{m+n}\right\} \\
& \text { of } T_{5, n} \text { and }|S|=3+i .
\end{aligned}
$$

- If $\mathrm{n}=2+3 \mathrm{i}+\mathrm{j}$, where $\mathrm{j}=2$ and $i=N \bigcup\{0\}$,

$$
\begin{aligned}
& \text { Consider the } \quad \text { set } \\
& S=\left\{v_{2+3 k} \backslash \mathrm{k}=0 \text { to } \mathrm{i}+1\right\} \bigcup\left\{v_{m+n-1}\right\} \\
& |S|=3+i .
\end{aligned}
$$

The above defined set $\mathrm{S}$ will be a dominating set as $v_{1+3 t}, v_{3+3 t} \in N\left(v_{2+3 t}\right)$ for $\mathrm{t}=0,1,2$ etc., Moreover we have $m\left(T_{5, n}-S\right)=2$.

Let $S_{1}$ be any other dominating set of $T_{5, n}$ with $m\left(T_{5, n}-S\right)>2$, then it is easily observed that $\left|S_{1}\right| \geq|S|$. So we have that,

$$
\left|S_{1}\right|+m\left(T_{5, n}-S_{1}\right)>|S|+m\left(T_{5, n}-S\right)
$$

Let $S_{2}$ be any other dominating set of $T_{5, n}$ with $m\left(T_{5, n}-S_{2}\right)=1$, then each component in $T_{5, n}-S_{2}$ is an isolated vertex and so we get $\left|S_{2}\right|>|S|$. Therefore,

$$
|S|+m\left(T_{5, n}\right)<\left|S_{2}\right|+m\left(T_{5, n}-S_{2}\right)
$$

Hence from (9) and (10), 


\section{Domination Integrity of Some Special Graphs}

$|S|+m\left(T_{5, n}-S\right)=\min \left\{|X|+m\left(T_{5, n}-X\right): \mathrm{X}\right.$ is a dominating set $\}$ $=D I\left(T_{5, n}\right)$

Case (ii) For $m=6$

- If $\mathrm{n}=2+3 \mathrm{i}+\mathrm{j}$, where $\mathrm{j}=0,1$ and $i=N \bigcup\{0\}$, consider the set $S=\left\{v_{3+3 k} \backslash \mathrm{k}=\mathrm{o}\right.$ to $\left.\mathrm{i}+1\right\} \bigcup\left\{v_{m+n}\right\}$ and $|S|=3+i$.

- If $\mathrm{n}=2+3 \mathrm{i}+\mathrm{j}$, where $\mathrm{j}=2$ and $i=N \bigcup\{0\}$, consider the set $|S|=\left\{v_{3+3 k} \backslash \mathrm{k}=0\right.$ to $\left.\mathrm{i}+1\right\} \bigcup\left\{v_{m+n-1}\right\}$ and $|S|=3+i$.

In the above two cases, the set $\mathrm{S}$ will be a dominating set since $v_{2+3 t}, v_{4+3 t} \in N\left(v_{3+3 t}\right)$ and also $v_{1} \in N\left(v_{6}\right)$ and for $\mathrm{t}=0$, 1,2etc. Moreover $m\left(T_{6, n}-S\right)=2$.

Let us consider $S_{1}$ any other dominating set with $m\left(T_{6, n}-S\right)=3$, then due to the nature of the structure we have $\left|S_{1}\right| \geq|S|$. So

$$
|S|+m\left(T_{6, n}-S\right)<\left|S_{1}\right|+m\left(T_{6, n}-S_{1}\right)
$$

Let $S_{2}$ be any other dominating set having $m\left(T_{6, n}-S_{2}\right)=1$, then each component of $T_{6, n}$ is isolated. So $\left|S_{2}\right|>|S|$. We can say that,

$$
\left|S_{2}\right|+m\left(T_{6, n}-S_{2}\right)>|S|+m\left(T_{6, n}-S\right)
$$

Therefore,

$|S|+m\left(T_{6, n}-S\right)=\min \left\{|X|+m\left(T_{6, n}-X\right): \mathrm{X}\right.$ is a dominating set $\}$ $=D I\left(T_{6, n}\right)$

Hence for $\mathrm{m}=5$ and 6 ,

$D I\left(T_{m, n}\right)=5+i$,if $\mathrm{n}=2+3 \mathrm{i}+\mathrm{j}$, where $\mathrm{j}=0,1,2$ and $\mathrm{i}=\mathrm{N} \bigcup\{0\}$

\section{E. Theorem}

For $m \geq 7$ and $n \geq 2$

$D I\left(T_{m, n}\right)=6+r+i$, if $\mathrm{m}=7+3 \mathrm{r}+\mathrm{s}, \mathrm{n}=2+3 \mathrm{i}+\mathrm{j}$ where $r=N \bigcup\{0\}, i=N \bigcup\{0\}$ and $\mathrm{s}=\mathrm{j}=0,1,2$.

\section{Proof}

To prove this result, we have to fix each value of $m$ and then allow $\mathrm{n}$ to vary from $2,3,4$ etc.

- If $\mathrm{m}=7+3 \mathrm{r}+\mathrm{s}$ and $\mathrm{n}=2+3 \mathrm{i}+\mathrm{j}$ where $r=i=N \bigcup\{0\}$, $\mathrm{s}=0,1,2$ and for $\mathrm{j}=0$ (that is for $m \geq 7$ and $\mathrm{n}=2,5$, $8,11,13 \ldots . .$.$) , consider the set$ $S=\left\{v_{3+3 t} \backslash \mathrm{t}=0\right.$ to $\left.\left\lfloor\frac{\mathrm{m}}{3}\right\rfloor-1\right\} \cup\left\{v_{m+3 k} \backslash \mathrm{k}=0\right.$ to $\left.\left\lfloor\frac{\mathrm{n}}{3}\right\rfloor\right\} \cup\left\{v_{m+n}\right\}$ as a dominating set and $|S|=4+r+i$.

- If $\mathrm{m}=7+3 \mathrm{r}+\mathrm{s}$ and $\mathrm{n}=2+3 \mathrm{i}+\mathrm{j}$ where $r=i=N \bigcup\{0\}, \mathrm{s}=$ $0,1,2$ and for $\mathrm{j}=1,2$ we consider the set $S=\left\{v_{3+3 t} \backslash t=0\right.$ to $\left.\left\lfloor\frac{\mathrm{m}}{3}\right\rfloor-1\right\} \cup\left\{v_{m+3 k} \backslash k=0\right.$ to $\left.\left\lfloor\frac{\mathrm{n}}{3}\right\rfloor\right\} \quad$ as $\quad$ a dominating set and $|S|=4+r+i$.

Further we have $m\left(T_{m, n}-S\right)=2$ and so $|S|+m\left(T_{m, n}-S\right)=6+r+i$.

Now to verify the minimality of $|S|+m\left(T_{m, n}-S\right)$.
Let us consider any other dominating set $S_{1}$, with $m\left(T_{m, n}-S_{1}\right)<2$, then all the components in $T_{m, n}-S_{1}$ are isolated. So we get $\left|S_{1}\right|>|S|$. Therefore,

$$
\left|S_{1}\right|+m\left(T_{m, n}-S_{1}\right)>|S|+m\left(T_{m, n}-S\right)
$$

Now consider other possible dominating set $S_{2}$ with $m\left(T_{m, n}-S_{1}\right)>2$, then due to the structural nature of the graph we have $\left|S_{2}\right| \geq|S|$. So

$$
\left|S_{2}\right|+m\left(T_{m, n}-S_{2}\right)>|S|+m\left(T_{m, n}-S\right)
$$

Therefore from (13) and (14),

$$
\begin{aligned}
|S|+m\left(T_{m, n}-S\right) & =\min \left\{X \mid+m\left(T_{m, n}-X\right): \mathrm{X} \text { is a dominating set }\right\} \\
& =\operatorname{DI}\left(T_{m, n}\right) .
\end{aligned}
$$

Hence,

$D I\left(T_{m, n}\right)=6+r+i$, if $\mathrm{m}=7+3 \mathrm{r}+\mathrm{s}, \mathrm{n}=2+3 \mathrm{i}+\mathrm{j}$ where $r=N \bigcup\{0\}, i=N \bigcup\{0\}$ and $\mathrm{s}=\mathrm{j}=0,1,2$.

\section{F. Theorem}

$D I\left(L_{r, s}\right)=\left\{\begin{array}{cc}r, & \mathrm{r} \geq 3 \text { and } \mathrm{s}=1, \\ r+1+i, & \mathrm{r} \geq 3 \text { and } \mathrm{s}=2+3 i+j\end{array} ;\right.$

where $\mathrm{i}=\mathrm{N} \cup\{0\}$ and $\mathrm{j}=0,1,2$.

\section{Proof}

Let $\left|V\left(L_{r, s}\right)\right|=r+s$. To prove this result we have to fix each value of $r$ and allow $s$ to vary from $0,1,2, \ldots$.

Case (i)

For $\mathrm{r}=3,4,5, \ldots \ldots$ and $\mathrm{s}=1$, Consider the set $S=\left\{v_{r}\right\}$ and $|S|=1$, then this $\mathrm{S}$ will be dominating set as $v_{r+1}, v_{r-1}, v_{r-2}, \ldots, v_{1} \in N\left(v_{r}\right)$. Further we have $m\left(L_{r, s}-S\right)=r-1$. So $|S|+m\left(L_{r, s}-S\right)=1+r-1=r$.

Now to check the minimality of $|S|+m\left(L_{r, s}-S\right)$.

Let us consider $S_{1}$ any other dominating set with $m\left(L_{r, s}-S_{1}\right)>m\left(L_{r, s}-S\right)$, then due to the nature of construction of the graph $L_{r, s}$ we have $\left|S_{1}\right| \geq|S|$. Therefore,

$$
\left|S_{1}\right|+m\left(L_{r, s}-S_{1}\right) \geq|S|+m\left(L_{r, s}-S\right)
$$

Now choose $S_{2}$ any other dominating set with $m\left(L_{r, s}-S_{2}\right)<m\left(L_{r, s}-S\right)$, then each component of $L_{r, s}-S_{2}$ will be isolated vertex. So $\left|S_{2}\right|>|S|$. Therefore,

$$
\left|S_{2}\right|+m\left(L_{r, s}-S_{2}\right)>|S|+m\left(L_{r, s}-S\right)
$$

Hence from (15) and (16), we have

$|S|+m\left(L_{r, 1}-S\right)=\min \left\{|X|+m\left(L_{r, 1}-S\right): \mathrm{X}\right.$ is a dominating set $\}$

$$
=D I\left(L_{r, 1}\right) \text {. }
$$

Case (ii)

For $r \geq 3$ and $\mathrm{s}=2+3 \mathrm{i}+\mathrm{j}$ where $i=N \bigcup\{0\}$ and $\mathrm{j}=0,1,2$

- If $r \geq 3$ and $\mathrm{s}=2+3 \mathrm{i}+\mathrm{j}$ where $i=N \bigcup\{0\}$ and $\mathrm{j}=0$ (i.e. for $\mathrm{s}=2,5,8,11, \ldots \ldots \ldots$ ), consider the set 


$$
\begin{aligned}
& S=\left\{v_{r+3 k} \backslash k=0 \text { to i }\right\} \bigcup\left\{v_{r+s}\right\} \quad \text { and also } \\
& |S|=2+i .
\end{aligned}
$$

- If $r \geq 3$ and $\mathrm{s}=2+3 \mathrm{i}+\mathrm{j}$ where $i=N \bigcup\{0\}$ and $\mathrm{j}=1,2$

(i.e. for $s=34,6,7,9,10 \ldots$ ), consider the set $S=\left\{v_{r+3 k} \backslash \mathrm{k}=0\right.$ to $\left.\mathrm{i}+1\right\}$ and $|S|=2+i$.

The above mentioned $\mathrm{S}$ will be a dominating set as $v_{r+1}, v_{r-1}, v_{r-2}, \ldots . ., v_{1} \in N\left(v_{r}\right)$ and $v_{r+3 t-1}, v_{r+3 t+1} \in N\left(v_{r+3 t}\right)$ where $\mathrm{t}=1,2,3,4 \ldots \ldots$ Moreover we have $m\left(L_{r, s}-S\right)=r-1$.

Therefore,

$|S|+m\left(L_{r, s}-S\right)=2+i+r-1=r+i+1$.

Now to check the minimum of $|S|+m\left(L_{r, s}-S\right)$.

Let us consider any other dominating set $S_{1}$ with $m\left(L_{r, s}-S_{1}\right)>m\left(L_{r, s}-S\right)$, then due to the nature of the structure we have $\left|S_{1}\right| \geq|S|$. Therefore,

$$
\left|S_{1}\right|+m\left(L_{r, s}-S_{1}\right) \geq|S|+m\left(L_{r . s}-S\right)
$$

Now consider another dominating set $S_{2}$ with $m\left(L_{r, s}-S_{2}\right)<m\left(L_{r, s}-S\right)$, then each component in $L_{r, s}-S_{2}$ will be an isolated vertex and so $\left|S_{2}\right|>|S|$. Therefore,

$$
|S|+m\left(L_{r, s}-S\right)<\left|S_{2}\right|+m\left(L_{r, s}-S_{2}\right)
$$

From (17) and (18), we conclude that

$$
\begin{aligned}
|S|+m\left(L_{r, s}-S\right) & =\min \left\{|X|+m\left(L_{r, s}-S\right): \text { X is a dominating set }\right\} \\
& =D I\left(L_{r, s}\right)
\end{aligned}
$$

Hence,

$$
D I\left(L_{r, s}\right)=\left\{\begin{array}{cc}
r, & \mathrm{r} \geq 3 \text { and } \mathrm{s}=1, \\
r+1+i, & \mathrm{r} \geq 3 \text { and } \mathrm{s}=2+3 i+j
\end{array}\right.
$$

\section{G. Theorem}

$$
D I\left(L\left(P_{n}\left[P_{2}\right]\right)\right)= \begin{cases}5, & n=2, \\ 9, & n=3, \\ 11, & n=4\end{cases}
$$

\section{Proof}

Let $u_{1}, u_{2}, u_{3}, \ldots . u_{n}$ be vertices of the path $P_{n}$ and $v_{1}, v_{2}$ be the vertices of the path $P_{2}$. Let $L\left(P_{n}\left[P_{2}\right]\right)$ be the line graph of composition of $P_{n}$ and $P_{2}$ with $\left|V\left(L\left(P_{n}\left[P_{2}\right]\right)\right)\right|=q$ (that is, $\left.e_{1}, e_{2}, e_{3}, \ldots . e_{q}\right)$ and the cardinality of edge set of $L\left(P_{n}\left[P_{2}\right]\right)$ is $\left|E\left(L\left(P_{n}\left[P_{2}\right]\right)\right)\right|=-q+\frac{1}{2}\left[\sum\left(d\left(v_{i}\right)\right)^{2}\right]$. We need the following three cases to prove the result.

Case (i)

For $\mathrm{n}=2$

Let us consider the dominating set $S=\left\{e_{1}, e_{3}, e_{5}, e_{6}\right\}$ of $L\left(P_{n}\left[P_{2}\right]\right)$. Then $|S|=4$ and $m\left(L\left(P_{2}\left[P_{2}\right]\right)-S\right)=1$. So $|S|+m\left(L\left(P_{2}\left[P_{2}\right]\right)-S\right)=5$. Also for $S=\left\{e_{2}, e_{4}, e_{5}, e_{6}\right\}$ we get
$|S|+m\left(L\left(P_{2}\left[P_{2}\right]\right)-S\right)=5$. For other choice of $S=\left\{e_{1}, e_{3}\right\}$ or $S=\left\{e_{2}, e_{4}\right\} \quad, \quad$ then $m\left(L\left(P_{2}\left(P_{2}\right)\right)-S\right)=4 \quad$ and $|S|+m\left(L\left(P_{2}\left[P_{2}\right]\right)-S\right)=6$. So $|S|+m\left(L\left(P_{2}\left[P_{2}\right]\right)-S\right)=5$ will be the minimum. Therefore, $\operatorname{DI}\left(L\left(P_{2}\left[P_{2}\right]\right)\right)=5$.

\section{Case(ii)}

For $n=3$

Consider the set $S=\left\{e_{3}, e_{6}, e_{7}, e_{8}, e_{9}, e_{10}, e_{11}\right\}$ as a dominating set of $L\left(P_{3}\left[P_{2}\right]\right)$ and $|S|=7$. Moreover $m\left(L\left(P_{3}\left[P_{2}\right]\right)-S\right)=1$. So $|S|+m\left(L\left(P_{3}\left[P_{2}\right]\right)-S\right)=9$. For other choice of $S=\left\{e_{1}, e_{3}, e_{5}, e_{7}, e_{8}\right\}$ and $m\left(L\left(P_{3}\left[P_{2}\right]\right)-S\right)=5$, then $|S|+m\left(L\left(P_{3}\left[P_{2}\right]\right)-S\right)=10$. Hence $|S|+m\left(L\left(P_{3}\left[P_{2}\right]\right)-S\right)=9$ is minimum. Therefore, $\operatorname{DI}\left(L\left(P_{3}\left[P_{2}\right]\right)\right)=9$.

\section{Case (iii)}

For $\mathrm{n}=4$, Consider the set $S=\left\{e_{2}, e_{4}, e_{6}, e_{8}, e_{12}, e_{13}\right\}$ as a dominating set of $L\left(P_{4}\left[P_{2}\right]\right)$ and $|S|=6$. Then $m\left(L\left(P_{4}\left[P_{2}-S\right]\right)\right)=5$. Therefore, $|S|+m\left(L\left(P_{4}\left[P_{2}\right]\right)-S\right)=11$. If we consider the other dominating set $S=\left\{e_{1}, e_{3}, e_{5}, e_{7}, e_{9}, e_{10}, e_{15}, e_{16}\right\}$, then $m\left(L\left(P_{4}\left[P_{2}\right]\right)-S\right)=6$ So $|S|+m\left(L\left(P_{4}\left[P_{2}\right]\right)-S\right)=14$. Hence $|S|+m\left(L\left(P_{4}\left[P_{2}\right]\right)-S\right)=11$ is minimum. Therefore $\operatorname{DI}\left(L\left(P_{4}\left[P_{2}\right]\right)\right)=11$.

Hence, $D I\left(L\left(P_{n}\left[P_{2}\right]\right)\right)= \begin{cases}5, & n=2, \\ 9, & n=3, \\ 11, & n=4\end{cases}$

\section{H. Theorem}

For $5 \leq n \leq 14$

$\operatorname{DI}\left(L\left(P_{n}\left[P_{2}\right]\right)\right)=15+4 i+j$, where $\mathrm{i}=0,1,2,3$ and 4, $\mathrm{j}=0,1$.

Proof

If $\mathrm{n}=5+2 \mathrm{i}+\mathrm{j}$, where $\mathrm{i}=0,1,2,3,4$ and $\mathrm{j}=0,1$ (i.e., for $\mathrm{n}=5$, $6,7, \ldots .13,14), \quad$ consider the set $S=\left\{e_{2+2 t} \backslash \mathrm{t}=0\right.$ to $\left.\mathrm{i}+2\right\} \bigcup\left\{e_{2 n-2 t} \backslash \mathrm{t}=0\right.$ to $\left.\mathrm{i}+\mathrm{j}+1\right\} \bigcup\left\{e_{2 n+4+6 t}, e_{2 n+5+6 t} \backslash \mathrm{t}=0\right.$ to $\left.\mathrm{i}+1\right\}$ and $|S|=9+4 i+j$. The above mentioned set $S$ is a dominating set of $L\left(P_{n}\left[P_{2}\right]\right)$ as $e_{2 n+2+6 t} \in N\left(e_{2 n+4+6 t}\right), e_{1+2 t}, e_{3+3 t}, e_{2 n+3+6 t}, e_{2 n+6+6 t} \in N\left(e_{2 n+4+6 t}\right)$, and $e_{2 n+1+6 t} \in N\left(e_{2 n+5+6 t}\right)$. Moreover $m\left(L\left(P_{n}\left[P_{2}\right]\right)-S\right)=6$. So $|S|+m\left(L\left(P_{n}\left[P_{2}\right]\right)\right)=15+4 i+j$.

Now to verify the minimum of $|S|+m\left(L\left(P_{n}\left[P_{2}\right]\right)-S\right)$.

Let $S_{1}$ be any other dominating set with $m\left(L\left(P_{n}\left[P_{2}\right]\right)-S\right)=10$ or $m\left(L\left(P_{n}\left[P_{2}\right]\right)-S\right)=14$, then due to the nature of the structure of $L\left(P_{n}\left[P_{2}\right]\right)$ in both the cases we get $\left|S_{1}\right| \leq|S|$. But,

$$
|S|+m\left(L\left(P_{n}\left[P_{2}\right]\right)-S\right) \leq\left|S_{1}\right|+m\left(L\left(P_{n}\left[P_{2}\right]\right)-S_{1}\right)
$$

The other possible dominating set $S_{2}$ of $L\left(P_{n}\left[P_{2}\right]\right)$ with $m\left(L\left(P_{n}\left[P_{2}\right]\right)-S\right)<6$, then each component in $L\left(P_{n}\left[P_{2}\right]\right)$ will be isolated and so $\left|S_{2}\right|>|S|$. Therefore, 


$$
\left|S_{2}\right|+m\left(L\left(P_{n}\left[P_{2}\right]\right)-S_{2}\right)>|S|+m\left(L\left(P_{n}\left[P_{2}\right]\right)-S\right)
$$

From (19) and (20), we get

$|S|+m\left(L\left(P_{n}\left[P_{2}\right]\right)-S\right)$

$$
\begin{aligned}
& =\min \left\{|X|+m\left(L\left(P_{n}\left[P_{2}\right]\right)-X\right): \mathrm{X} \text { is a dominating set }\right\} \\
& =D I\left(L\left(P_{n}\left[P_{2}\right]\right)\right)
\end{aligned}
$$

Hence for $5 \leq n \leq 14$, $D I\left(L\left(P_{n}\left[P_{2}\right]\right)\right)=15+4 i+\mathrm{j}$, where $\mathrm{i}=0,1,2,3,4$ and $\mathrm{j}=0,1$

\section{Theorem}

For $n \geq 15 D I\left(L\left(P_{n}\left[P_{2}\right]\right)\right)=n+8 i+18$, if $\mathrm{n}=15+9 i+4 \sum_{p=0}^{i} p$, where $i=N \bigcup\{0\}$ and also the Domination integrity for $\mathrm{n} \neq 15+9 i+4 \sum_{p=0}^{i} p$.

\section{Proof}

To give the result we need the following two cases.

Case (i)

If $\mathrm{n}=15+9 i+4 \sum_{p=0}^{i} p$, where $i=N \bigcup\{0\}$ (i.e., for $\mathrm{n}=15,28,45,66 \ldots)$, and let us consider the dominating set of $L\left(P_{n}\left[P_{2}\right]\right)$ as $S=\left\{e_{(3+i)(1+t)}, e_{2 n+3(k+1)+3 t(3+i)}, e_{2 n-t(3+i)} \backslash t=0 t o\left(\frac{n}{3+i}\right)-1\right.$ and $k=0 t o i\} \bigcup\left\{e_{2 n+1+3(i+2)+3 t(i+3)}, e_{2 n+2+3(i+2)+3 t(i+3)} \backslash t=0 t o\left(\frac{n}{3+i}\right)-2\right\}$ and $|S|=n+4(i+2)$. Moreover $m\left(L\left(P_{n}\left[P_{2}\right]\right)-S\right)=10+4 i$. Therefore, $|S|+m\left(L\left(P_{n}\left[P_{2}\right]\right)-S\right)=n+8 i+18$.

Now to analyze the minimum of $|S|+m\left(L\left(P_{n}\left[P_{2}\right]\right)-S\right)$.

Let $S_{1}$ be any other dominating set of $L\left(P_{n}\left[P_{2}\right]\right)$ with $\left|S_{1}\right|<|S|$, then due to the nature of the construction of the graph $L\left(P_{n}\left[P_{2}\right]\right) \quad, \quad$ we have $m\left(L\left(P_{n}\left[P_{2}\right]\right)-S_{1}\right)>m\left(L\left(P_{n}\left[P_{2}\right]\right)-S\right)$ such that

$$
|S|+m\left(L\left(P_{n}\left[P_{2}\right]\right)-S\right) \leq\left|S_{1}\right|+m\left(L\left(P_{n}\left[P_{2}\right]\right)-S_{1}\right)
$$

Let $S_{2}$ be any dominating set of $L\left(P_{n}\left[P_{2}\right]\right)$ with $\left|S_{2}\right|>|S|$, then $m\left(L\left(P_{n}\left[P_{2}\right]\right)-S\right)<m\left(L\left(P_{n}\left[P_{2}\right]\right)-S_{2}\right)$. So

$$
|S|+m\left(L\left(P_{n}\left[P_{2}\right]\right)-S\right) \leq\left|S_{2}\right|+m\left(L\left(P_{n}\left[P_{2}\right]\right)-S_{2}\right)
$$

From (21) and (22), we get

$$
\begin{aligned}
|S|+ & m\left(L\left(P_{n}\left[P_{2}\right]\right)-S\right) \\
& =\min \left\{|X|+m\left(L\left(P_{n}\left[P_{2}\right]\right)-X\right): \mathrm{X} \text { is a dominating set }\right\} \\
& =\operatorname{DI}\left(L\left(P_{n}\left[P_{2}\right]\right)\right)
\end{aligned}
$$

Hence, $D I\left(L\left(P_{n}\left[P_{2}\right]\right)\right)=n+8 i+18$, if $\mathrm{n}=15+9 i+4 \sum_{p=0}^{i} p$.

\section{Case (ii)}

For $n \neq 15+9 i+4 \sum_{p=0}^{i} p$
The number of terms in between $n=15+9 i+4 \sum_{p=0}^{i} p$ where $i=N \bigcup\{0\}$ (i.e., $\mathrm{n}=15,28,45,66 \ldots$ ) are $12+4 \mathrm{i}$. We can generate the four groups for the number of terms in between the $\mathrm{n}$. The number of members (or elements) in each group are $\frac{12+4 i}{4}=3+i$, for $i=N \bigcup\{0\}$. Then the first member in each group have domination integrity value is computed by adding 3 to the previous domination integrity value and the other members of each groups have consecutive numbers as their domination integrity value.

\section{CONCLUSION}

The network users and designers give much more preference to it's stability. Here we have analyzed the one of the parameter known as domination integrity and is used to find the vulnerability of a network. We investigated the domination integrity Tadpole, Lollipop graph and line graph formed from the composition of $P_{n}$ and $P_{2}$ and we conclude that the order of the graph increases, then the domination integrity value also increases. The Domination integrity of some graph operations on tadpole, lollipop, snake and grid graphs are an open are for investigation.

\section{REFERENCES}

1. T. Haynes, S. Hedetniemi, and P. Slater, Fundamentals of Domination in Graphs, Marcel Dekker, New York, NY, USA, 1998.

2. R. Sundareswaran, and V. Swaminathan, "Domination integrity in graphs", Proceedings of International Conference on Mathematical and Experimental Physics, Narosa Publishing House, pp. 46-57, 2010.

3. R. Sundareswaran, and V. Swaminathan, "Domination Integrity of Powers of Cycles", International Journal of Mathematical Research, vol.3(3), pp. 257-265, 2011.

4. R. Sundareswaran, and V. Swaminathan, "Domination Integrity of Middle Graphs", Algebra, Graph Theory and their Applications, Tamizh Chelvam T., Somasundaram S., and Kala R., eds., Narosa Publishing House, 2010, pp. 88-92, 2010.

5. R. Sundareswaran, and V. Swaminathan, "Domination Integrity in Trees", Bulletin of International Mathematical Virtual Institute, ISSN 1840-4367,2, pp. 153-161, 2012

6. Sultan Senna Mahde and Veena Mathad, "Domination Integrity of Line Splitting Graph and Central Graph of Path, Cycle and Star Graphs”, AAM International Journal, Vol.11, issue 1, pp. 408-423, 2016.

7. S.K. Vaidya, and N. J. Kothari, "Some new results on domination integrity of graphs", Open J. Discrete Math. Vol. 2, pp. 96-98, 2012.

8. S. K. Vaidya, and N. J. Kothari, "Domination integrity of Splitting graph of path and cycle", ISRN Combin. 2013, Article ID 795427, 7 pp., 2013.

9. S. K. Vaidya, and N. J. Kothari, "Domination integrity of splitting and degree splitting graphs of some graphs", Advances and Applications in Discrete Mathematics, vol. 17 no. 2 pp. 185-199, 2016.

10. S. K. Vaidya, and N. H. Shah, "Domination integrity of shadow graphs",(2013), In: Advances in Domination Theory II, (edited by V. R. Kulli), Vishwa International Publications, pp. 19-31.

11. S. K. Vaidya, and N. H. Shah, "Domination integrity of total graphs", TWMS J. Appl. Engin. Math.,vol.4(1), pp. 117-126, 2014

12. S. K. Vaidya, and N. H. Shah, "Domination integrity of some path related graphs", Appl. Appl. Math.: An Inter. J., vol. 9(2), pp. 780-794, 2014.

13. D. B. West, Introduction to Graph Theory, 2nd ed., Prentice-Hall of India, New Delhi, 2003. 